\title{
Comparison of conventional, amplitude-integrated and geodesic sensor net EEG used in premature neonates: a systematic review
}

\author{
Comparação do uso do EEG convencional, EEG de amplitude integrada e EEG geodésico \\ em neonatos prematuros: uma revisão sistemática
}

\author{
Tainã Maria Alves de SOUSA', Vinicius Siessere GUGELMIN¹, Geraldo Magela FERNANDES', Carlos \\ Nogueira AUCÉLIO' ${ }^{1}$ Karina Nascimento COSTA', Rosana Maria TRISTÃO'
}

\begin{abstract}
The use of methods to evaluate cortical activity in neonates has great importance in modern medicine, as it allows the observation and evaluation of several clinical aspects, which guarantees that the health team has knowledge about possible intervention measures that may be necessary in the treatment of newborns. Objective: This systematic review aimed to compare the main technologies available for the evaluation of brain functions in neonates, among them: the conventional electroencephalogram (EEG), the amplitude-integrated electroencephalogram (aEEG) and the geodesic sensor net EEG. Methods: A search was conducted forarticles from national and international periodicals included in the Web of Science, LILACS, SciELO and Medline electronic databases. Results: The search found 39 among 155 articles of interest and the analyses indicated that, in the clinical environment, the use of both conventional EEG and aEEG is highly recommended, as the combination of their functions allows, for example, a greater number of subclinical seizures to be detected. Conversely, the use of a geodesic sensor net EEG could be of great value, as it allows a large amount of data to be analyzed. Conclusion: This analysis may be useful in studies and research related to diseases and symptoms, such as seizures, a current challenge for neonatal neuromonitoring, as well as aspects of neurological development and functional studies. However, despite many advances in technology, electroencephalography in preterm neonates remains a challenge worldwide and still requires more robust research and efforts towards the best clinical assistance in this extremely early stage of life.
\end{abstract}

Keywords: Electroencephalograhy; intensive care units, neonatal; seizures.

\begin{abstract}
RESUMO
Métodos para avaliar a atividade cortical em neonatos têm grande importância na Medicina moderna, pois permitem a observação e avaliação de diversos aspectos clínicos, garantindo que a equipe de saúde tenha conhecimento sobre possíveis medidas de intervenção que possam ser necessárias no tratamento de recém-nascidos. Objetivo: Esta revisão sistemática tem como objetivo comparar as principais tecnologias disponíveis para a avaliação das funções cerebrais em neonatos: eletroencefalograma convencional (EEG), eletroencefalograma de amplitude integrada (aEEG) e eletroencefalograma da rede do sensor geodésico. Métodos: Os artigos foram selecionados em periódicos nacionais e internacionais, incluídos nas bases de dados eletrônicas Web of Science, LILACS, SciELO e Medline. Resultados: Foram encontrados 39 artigos de interesse entre 155 artigos. As análises indicaram que, em relação ao ambiente clínico, o uso associativo de EEG convencional e aEEG é altamente recomendado, pois permite a combinação de funções, facilitando, por exemplo, que um maior número de convulsões sub-clínicas seja detectado. Por outro lado, o uso do eletroencefalograma da rede do sensor geodésico seria de grande valor, uma vez que permite que uma grande quantidade de dados seja analisada. Conclusão: Essa análise pode ser útil em estudos e pesquisas relacionados a doenças e sintomas, como convulsões, um desafio atual para a neuromonitorização neonatal, bem como aspectos de desenvolvimento neurológico e estudos funcionais. No entanto, apesar de muitos avanços tecnológicos, a eletroencefalografia em recém-nascidos prematuros ainda é um desafio em todo o mundo e requer pesquisas e esforços mais robustos para a melhor assistência clínica neste estágio extremamente precoce da vida.
\end{abstract}

Palavras-chave: Eletroencefalografia; Unidades de terapia intensiva neonatal; convulsões.

\footnotetext{
1 Universidade de Brasília, Faculdade de Medicina, Área de Medicina da Criança e do Adolescente, Brasília DF, Brasil. Tainã Maria Alves de Sousa (ID https://orcid.org/0000-0002-8570-0166; Vinicius Siessere Gugelmin iD https://orcid.org/0000-0002-1724-068X; Geraldo Magela Fernandes (iD https://orcid.org/0000-0002-4347-8886; Carlos Nogueira Aucelio (iD) https://orcid.org/0000-0002-2170-9874; Karina Nascimento Costa (iD https://orcid.org/0000-0002-3095-971X; Rosana Maria Tristão (iD) https://orcid.org/0000-0002-1751-8506 Correspondence: Rosana Maria Tristão; Faculdade de Medicina; Campus Universitário Darcy Ribeiro; 70910-900 Brasília DF, Brasil; E-mail: rmtt@unb.br Conflict of interest: There is no conflict of interest to declare.

Received 08 October 2018; Accepted 09 December 2018.
} 
Neurological evaluation in neonates in recent years has raised doubts about the choice of electroencephalographic methods and equipment available. The main devices in clinical and laboratory use are the conventional electroencephalogram (EEG), the amplitude-integrated EEG (aEEG) and the geodesic sensor net EEG. Their different types of inbuilt technology, data presentation and coverage of brain function have led to studies about their positive and negative aspects in the evaluation of newborns. In general, of the three mentioned above, conventional EEG is the most used in routine care. It makes the analysis of several aspects of a newborn's health and neurodevelopment possible by evaluating the sleep-wake cycle and brain's maturation, detecting seizures and consequences of non-neurological diseases. The use of aEEG in the neonatal intensive care unit (NICU) has generated doubts about the efficacy of its use in the neonatal care routine due to the reduction of data, making its analysis questionable when not carefully assessed. The geodesic sensor net EEG is a new technology that is not commonly used in the clinical routine, and the main reasons for this are the costs of the device and the lack of research about the efficacy of its use, which has led researchers and the teams in NICUs to question whether this technology is suitable for clinical use.

Although conventional EEG is still the most common in many hospitals, some specific demands of the NICU, related to the time needed for analysis, type, quantity and positioning of the electrodes and interpretation of the tests, have led health professionals to seek alternatives. However, the great difference between some of the aspects of these three techniques makes the cost-benefit assessment difficult, since the acquisition of only one of these devices may limit the diagnoses and prognoses being made with precision. Several doubts about the effectiveness, operation and use of these devices inspired the creation of this review, which will define each of these technologies, indicate their possible uses and limitations, and compare their use in newborn infants, with a focus on preterm infants.

\section{METHODS}

The bibliographic survey, carried out in January of 2018, was based on the analysis of the Web of Science, LILACS (Latin American and Caribbean Health Sciences Literature), SciELO (Scientific Electronic Library Online) and Medline (Medical Literature Analysis and Retrieval System Online) databases. The controlled descriptors used were "EEG", leading to 93,646 articles, then the descriptor "neonate" was used, refining the research to 833 articles, and lastly the descriptor "premature", resulting in 155 articles. Among them, 79 were excluded because they were related to specific cases and diseases or because they described technical subjects related to the apparatus and the way of analyzing the data. The final pool included 39 articles, which were appropriate for the comparison of EEG methods and analysis of their application.

\section{RESULTS}

\section{Conventional electroencephalogram}

In this method, the registration of each channel of the EEG is made from the potential difference between a derivation, which can be of two types: monopolar or bipo$\operatorname{lar}^{1}$. A monopolar derivation is measured by the difference between the potentials of an electrode and a reference voltage. In the bipolar derivation, the difference in potential between two electrodes is measured, so the signal does not have a common reference. The latter does not allow direct comparisons of amplitude between the channels, although it allows the observer to obtain better localized responses in space, because the electrical signals that appear on all the electrodes cancel each other out in the differential measure ${ }^{2}$.

The use of continuous EEG, which is the use of EEG for uninterrupted monitoring for at least three hours, is a frequent occurrence in the $\mathrm{NICU}^{3,4}$ and is recognized by the current literature as having a good cost-benefit ratio ${ }^{3,5}$. Seizures are one of the examples of clinical situations that would be undetectable without the use of continuous $\mathrm{EEG}^{3-6}$, as in one third of cases they are subclinical, occurring silently ${ }^{6,7}$. It has been shown that the delay in initiating continuous EEG monitoring in critical cases is directly associated with increased mortality, as well as the time to admission in the $\mathrm{NICU}^{3}$. The gold standard for the initial assessment of the neonate's brain functioning is conventional video-EEG ${ }^{8}$, which differs from EEG in its inclusion of a video record of the examination period. The use of video-EEG in neonates allows the investigation of the progress of cerebral maturation, as it favors the improvement of therapeutic interventions related to the treatment of the newborn?.

The recognition of sleep-wake states through the application of an EEG can be useful in assessing optimal periods for breastfeeding and care of newborns, as well as improving the sleep of newborns in NICUs, especially in children with problems related to sleep, such as increased risk of sudden infant death syndrome and sleep apnea ${ }^{9}$. For sleep analysis, the duration of the EEG should be at least three to four hours and one complete sleep-wake cycle ${ }^{8}$. However, EEG sleep detection may be challenging in neonates, who are in a period of rapid brain maturation, due to both the biological variability among the babies and the different techniques that can be used in the test. In very premature babies in critical condition, for example, this method can be considered very intrusive. Conventional video-EEG-polysomnography studies use a combination of the child's behavioral traits and EEG parameters for the visual classification of sleep-wake cycles, as none of these characteristics alone are considered 
the gold standard 9 . This can be done using several assemblies with electrodes placed according to the international 10-20 system $^{10}$, adapted for newborns, and five polygraph channels, two for eye movement detection, one for chin muscle activity, one for chest movement, and one for electrocardiogram recognition ${ }^{8}$. Currently, the American Academy of Sleep Medicine suggests the recognition of continuous and discontinuous patterns in EEG to assess sleep states of children between zero and two months, as there is complexity in the evaluation of EEG standards and a high index of discrepancy in the classification of sleep among the evaluators ${ }^{8,9}$.

Similarly, for other studies, the EEG has been a valid method to evaluate the neurocognitive function and prognosis of the premature neonate in NICU. It is a valid method of measuring maturation, as well as functional impairment of the brain ${ }^{11}$. The connectivity presented by the EEG, which is one of the aspects evaluated during this examination, reflects the synchronization of neural function within an area or between distant parts of the cerebral cortex, which require both structural and functional connections ${ }^{11,12}$. Clinical studies have demonstrated the importance of interhemispheric synchrony as a marker of neonatal EEG activity that shows normal child development ${ }^{13}$, and recent studies have focused on the phase synchronization present between EEG oscillations ${ }^{12}$.

Quantitative EEG characteristics are spectral analyses that decompose the EEG signal into its constituent frequency components ${ }^{9}$, which in turn define the discontinuity in neonatal EEG ${ }^{9,14}$. This discontinuous activity may reflects important transient therapeutic pathways for cortical development, which indicates the EEG's efficiency as a sensitive measure of functional maturation ${ }^{11}$ and neurological damage in preterm infants ${ }^{15}$. It has already been analyzed that, even though the extrauterine life of neonates influences behavioral patterns during sleep, it does not have an influence on accelerating the maturation of EEG patterns ${ }^{16,17}$.

The knowledge of neural connectivity in neonates has also been fundamental for the study of the consequences of non-neurological diseases that affect neonates. To evaluate the influence of congenital heart disease on the characteristics of the neural connectivity networks in the affected neonates, these infants underwent continuous EEG monitoring, which confirmed that brain abnormalities developed by newborns with congenital heart disease may manifest as problems in the establishment of mature communication patterns between distant cortical areas ${ }^{11}$.

\section{Limitations of conventional EEG}

Although video-EEG monitoring is the gold standard for diagnosis and treatment, it is often not feasible or practical in the hectic daily routine of most NICUs ${ }^{4}$. The use of conventional EEG in the NICU requires the availability of time and staff with technical skill and experience in certain parame$\operatorname{ters}^{14,18}$, which is generally not readily available ${ }^{18}$. In addition, the EEG has limitations when it is necessary to use it for long-term brain monitoring, and the fact that it is recorded briefly and inconsistently, in periods of between 45 and 60 minutes, prevents the tracking of temporal patterns in brain electrical activity ${ }^{5}$.

Although the use of software for EEG analysis opens several opportunities for our understanding of premature infant brain activity, its use must still involve human participation, as the equipment is still unable to differentiate artifacts from actual brain activity ${ }^{16}$. The detailed interpretation of the results requires an expert professional, and the complete application of neonatal electrodes requires a trained per$\operatorname{son}^{5,14}$. In this regard, there is a call to use electrodes that do not hurt the sensitive skin of the baby, for example, the soft textile conductors, a particularly relevant feature in premature infants, especially in EEG monitoring over a long period of time. It may be possible to reduce painful stimuli, but this may alter the results of the examination, increasing the number of artifacts to be disregarded by the evaluators, resulting in difficulty in the EEG analysis ${ }^{5,19}$. In addition to pain ${ }^{19}$, other aspects may increase the number of artifacts present in neonatal examination, such as muscle activity ${ }^{5,20}$, especially in EEG recordings concentrated on frontal and temporal areas.

\section{Amplitude-integrated electroencephalogram}

The aEEG is based on the analysis of a reduced number of conventional EEG channels ${ }^{4,21,22}$, using one or two channels instead of the international 10-20 system placement of electrodes ${ }^{18,22}$, compressing and filtering the data and the time before its display ${ }^{22}$. Its basic interpretation is similar to that of conventional EEG, based on the recognition of background activity patterns ${ }^{4}$.

Normally, the cables are positioned in a single pair of biparietal sites (P3 and P4) or they can be altered to promote additional bonding on each side (C3 and $\mathrm{C} 4)^{4,14,18,23}$. Studies have shown that the bi-hemispheric method was superior due to its usefulness in monitoring children with unilateral brain injury, for example ${ }^{4,18}$. The method using four electrodes would also be advantageous because it allows an increase in the sensitivity of the device, by minimizing asymmetries and allowing a greater chance of detection of convulsive activity $^{14}$. The use of this two-channel aEEG (C3/P3, C4/P4) has recently been advocated, as it allows the detection of interhemispheric asymmetries and may also increase the diagnostic sensitivity of the device. A common way to make the placing of the electrodes easier, and to avoid their use on the scalp, is the positioning of these on the forehead. However, this situation is not advised for newborns because their frontal regions are electrophysiologically underdeveloped, and many seizures originating in other brain regions do not propagate consistently in this area ${ }^{5}$.

Lately, the use of this technique has been increasing, especially in NICUs ${ }^{24,25}$. This technique allows a continuous and noninvasive monitoring of brain function ${ }^{23,24,26}$, accessible as 
a bedside technology because of its compact $\operatorname{size}^{7,22}$, and it is very useful in assessing the maturation of electrocortical activity in preterm and full-term neonates in NICUs ${ }^{14,24,27}$. Regarding safety in the use of this technique in the NICU, although preterm infants are more vulnerable to tampering, there is a assurance in the use of aEEG to evaluate this population, as there is a low incidence (6\%) of adverse effects such as burns, accidental hair removal, hypothermia and desaturation $^{14}$. This type of care is recommended as a complement or an augmentation of NICU resources and may be useful for monitoring infants with clinical encephalopathy or suspected acute brain injury ${ }^{5,14}$, with clinical suspicion of seizure occurrence in cases such as in the absence of a conventional EEG, or in situations considered to be at high risk of acute brain injury ${ }^{5}$. It is also known that survival and long-term outcome after preterm labor may be predicted by the early recording of an $\mathrm{aEEG}^{27}$.

To analyze cortical activity, the device records the two main patterns of brain function, continuity and discontinuity, revealing cycling, which depicts the transition from one function to another ${ }^{28}$. It is known, for example, that the activity of the electrocortical background is more discontinuous during the first days of life, especially in extremely preterm infants ${ }^{4,14,21}$. Existing or developing pathological conditions may also be detected by aEEG screening, as exemplified by the recognition of periventricular leukomalacia and intraventricular hemorrhage ${ }^{14,24}$, represented by acute disturbances in the background activity on the aEEG tracing ${ }^{24}$, as well as in the detection of severe meningitis ${ }^{14}$. Currently, this technique, combined with a head ultrasound, has been used to detect the prognosis of low birth weight infants and to identify patients at risk ${ }^{21}$. An aEEG is also used in the evaluation of sleep and its related disorders in neonates ${ }^{23}$, in the surveillance of antiepileptic treatment ${ }^{27}$, in the detection of seizures $^{27}$, as part of the protocols for the evaluation of secondary neonatal encephalopathy, cerebral hemorrhages ${ }^{4}$, severe hypercapnia ${ }^{28}$, and hypoxic-ischemic encephalopathy $y^{4,618}$.

In the case of hemorrhages, the ones that affect premature neonates were associated with more discontinuous patterns, less developed sleep-wake cycles and a higher incidence of seizures, characteristics that can be detected by $\mathrm{aEEG}^{14}$. Severe hypercapnia results in profound depression of brain activity, which may be clearly visible in the aEEG tracing, although some children do not present with visible depression at similar levels of hypercapnia and have no change in quantitative EEG parameters ${ }^{28}$.

In hypoxic-ischemic encephalopathy, continuous aEEG is also indicated to evaluate the extent of brain damage and the early identification of brain injury in neonates ${ }^{4,18}$. The detection of the sleep-wake cycle and abnormal neural patterns by aEEG has been shown to be an essential tool in predicting a favorable neurological outcome in neonates with hypoxic-ischemic encephalopathy who have not undergone therapeutic hypothermia ${ }^{7,15}$.
The aEEG can be used to identify infants ${ }^{8,26}$ or neonates ${ }^{7,14}$ who may benefit from submission to hypothermia proto$\operatorname{cols}^{14,24}$, in addition to being able to predict the outcome of neonates undergoing this therapy. Studies have shown that aEEG, measured only three hours after birth, can predict the child's neurodevelopmental outcomes ${ }^{24}$, and the existence of normal aEEG patterns in newborns within the first 72 hours of life has also been shown to be a strong indication that they may survive without sequelae ${ }^{18}$.

Increasingly, aEEG is also cited in the literature for specific diseases and conditions that may affect the normal neurodevelopment of the neonate, especially premature infants. Placental lesions consistent with intrauterine infection with fetal involvement are one of the causes of the absence of aEEG cycling in the first day of life of those born at 28 weeks of gestation ${ }^{25}$. In addition, placental lesions consistent with low maternal perfusion were associated with depressed brain activity during the first two days of life and lower overall brain activity during the first three days of life. In contrast, placental lesions consistent with fetal thrombo-occlusive vascular disease of the inflammatory type were less likely to be associated with abnormal depressed brain activity in the recording of an aEEG on the first day of life, compared with those with placental lesions with low maternal perfusion ${ }^{25}$.

Among the advantages of this technique are the fact that its electrophysiological information is reduced and the time is compressed during the examination, which ensures that its monitoring and interpretation require less specific knowledge than the conventional $\mathrm{EEG}^{7,14,24}$, as well as the number and the simple placement of electrodes, which are easy to handle and allow easy application and understanding of the examination by the NICU team ${ }^{5}$. Another advantage is the possibility of detecting subclinical seizures when using aEEG for an extended time, which would go unnoticed in NICUs that do not have conventional EEGs for use over very long periods of time $\mathrm{e}^{7,24}$. The continuous monitoring of the aEEG allows the provision of data on the neonate's sleep-wake cycle, providing knowledge about appropriate moments of nursing care, possible medical interventions ${ }^{22}$ and the prognosis in term newborns ${ }^{15}$. In conventional EEG, because of the alternation between periods with and without measurable brain activity, sleep states may not be discernible ${ }^{23}$.

One of the most important uses of aEEG is in the detection of seizures ${ }^{4,15,18}$, which is essential in the evaluation of babies with low birth weight ${ }^{14}$ and in the selection of neonates who can be submitted to an intervention that aims to protect the nervous system ${ }^{15}$. One study revealed that electrographic seizures observed in the first week of life could be related to adverse outcomes that could affect the neonate in the future ${ }^{4}$. The interictal activity presented in newborns' seizures was related to their subsequent health status, as those who presented with convulsions with a normal amplitude aEEG had a normal evolution, while those with convulsions with a moderately abnormal or suppressed amplitude aEEG 
had a poor evolution of health status ${ }^{18}$. However, other studies have been questioning the efficacy of the exclusive use of aEEG in the detection of epileptic seizures, as it has a low and variable sensitivity (25-85\%) for the detection of neonatal seizures $^{14}$ and a low ability to detect convulsive activities of low duration and voltage, due to the small number of electrodes used in the examination ${ }^{4,5}$ or due to the reduced experience of the neonatologist in identifying the presence or absence of seizures ${ }^{18}$.

\section{Limitations of aEEG}

Among the limitations is that aEEG uses only one or two channels, which is its main drawback, because it allows the tracking of a very reduced area of the cerebral surface, which can result in the non-detection of some electrocortical activities, including some seizures. This makes the positioning of the electrodes a difficult task, which may lead to confusion when the aEEG is interpreted if this part is not well done ${ }^{24}$. Time compression, advantageous in detecting subclinical seizures and continuous monitoring, also has a negative side, as it becomes more difficult to detect lasting changes in brain activity without the concomitant use of a conventional $\mathrm{EEG}^{24}$. In addition, while carrying out an aEEG, it should be remembered that various external and internal factors may alter or cause changes in its bandwidth, such as interference caused by an electrocardiogram, high frequency oscillation ventilation, muscle activity, or the child's movement or handling, which need to be taken into account for the interpretation of results ${ }^{24}$. Medications administered to the newborn, such as sedatives and anticonvulsants, should also be considered, as they reduce signal continuity and result in lower border amplitude ${ }^{26}$.

\section{Coherence or geodesic sensor net electroencephalogram}

The geodesic sensor net EEG, or EEG coherence, is a method that evaluates the two-dimensional structure of the patient's head to collect a large amount of electroencephalographic data, rather than the old arrangement of the electrodes used in the 10-20 system ${ }^{29}$, which did not provide data on the two-dimensional surface of the head, but only of points on the measurement lines ${ }^{30}$. Attention is needed both for the appropriate distance between the electrodes on opposite sides of the head and the verification of the lower head coverage, in the regions below the ear and the face. Thus, even some regions that are already detected by the electrodes at the top can still be detected by the electrodes much more efficiently if they are positioned on the lower surface of the head ${ }^{31}$.

The geodesic sensor net EEG uses a lattice structure to store the large number of electrodes, which allows them to be placed correctly, to be applied simultaneously ${ }^{31}$, and to direct the compression of all points of the surface toward the center of the sphere, which holds them more efficiently on the surface of the head ${ }^{30}$. The lattice structure has between 32 and 256 channels, the first being the most common for routine examinations, in all cases offering full head coverage, including the standard sensor matrices of the $10-20$ system $^{31}$.

One of the parameters used by the system is coherence, which is the synchrony between two forms of the analyzed waves, meaning the synchrony of brain activity between two cortical regions ${ }^{32}$. The main reason for measuring this parameter is that it may show a similar brain function between two locations of the brain, thus assessing whether there is a functional synchrony between these regions, characterizing the prognosis in relation to the neonate's neurological development ${ }^{32}$. This is particularly relevant for the evaluation of the neurobehavioral outcome of preterm infants, because frontal cortical region function is known to be impaired by preterm labor ${ }^{32}$.

One study evaluated the influence of these parameters on the neural connection of neonates ${ }^{33}$. The objective was to evaluate the organization of functional networks of large-scale phase synchronization in brains of newborns during silent sleep and to explore their relationship with gestational age and variables that characterize possible prenatal influences on brain maturation. It was found that during the first two weeks after birth there was an increase in inter-hemispheric phase synchrony and a simultaneous decrease in the proportion of intra-hemispheric connections ${ }^{33}$. In addition, some features of functional connectivity network topologies were found to be associated with gestational age, suggesting that the differences that each one has in the organization of the functional network are related to the level of cortical maturity at birth ${ }^{33}$, which would be a risk factor for very premature children. Beyond the benefits of the positioning of electrodes already mentioned, no abrasion is required, reducing the risk of infection. Currently, this device has no restriction and can be applied from neonates to adults, without the need for sedation, including children who have behavioral deficits. With varying sizes, researchers are free to choose the right fit for the budget and for the age and type of participants in their study. It also offers the option, as does conventional EEG, of making standard, one- or two-hour, or extended recordings of up to 24 hours $^{31}$.

\section{Limitations of the geodesic sensor net EEG}

There is little information about the clinical use of the geodesic sensor net EEG, which makes it even more difficult to compare with the other two methods mentioned. What has been reported in this review is based on theoretical data, the manufacturer's assessments, and laboratory analyses that are not used clinically. The need for special equipment and specialized personnel to interpret and perform maintenance requires careful evaluation before being used in any project. 


\section{DISCUSSION}

Several studies have tried to compare the presented techniques from different angles. A lot of studies affirm the need for simultaneous use of aEEG with conventional EEG in NICUs ${ }^{4,5,10,15,18,24,34}$. One study found $80 \%$ sensitivity and specificity when using the two-channel aEEG in conjunction with conventional $\mathrm{EEG}^{4,35}$. Another study concluded that the use of aEEG should be simultaneous with that of conventional EEG, as in preterm newborns the discontinuous pattern may camouflage seizures ${ }^{24}$. Another factor that may make diagnosis difficult is that the interpretation of the aEEG is very dependent on the user ${ }^{16}$, and most neonatologists are not confident in their ability to interpret an aEEG tracing ${ }^{36}$. Although it has problems related to its interpretation, when used by experienced clinicians, aEEG has been shown to be of great relevance in providing an overview of conventional EEG activity ${ }^{37}$.

In seizure-related studies, it was found that both aEEG and conventional EEG may help to detect seizures, as well as allowing monitoring of the effect of treatment with antiepileptic drugs, analysis of background activity of the EEG and the characterization of diagnoses and prognostics ${ }^{38}$. However, with the low number of channels, not all seizures are detectable by aEEG ${ }^{34,37}$. Other studies have suggested the use of video-EEG to allow the analysis and validation of abnormal movements, such as epileptic seizures, and the location of the origin of possible artifacts ${ }^{24,38}$.

The use of the aEEG for the detection of neonatal seizures is controversial because of the fact that many of them last less than 90 seconds and are spatially restricted, which makes it very difficult to interpret the results ${ }^{10,18}$. Thus, it was concluded that the limited ability of aEEG to identify seizures does not allow it to be considered a substitute equivalent to a conventional EEG in terms of the detection of seizures ${ }^{10,37,38}$, although it has been stated that the use of an aEEG is recommended if there is no other electrographic monitoring ${ }^{10,38}$. The aEEG may be used initially in high-risk prematurity for long-term monitoring, with a conventional EEG used sequentially to assess more subtle abnormalities that are not described in an aEEG. Regarding the geodesic sensor net EEG, it is necessary to gather more information about its clinical use; however, it is cited as a good source for research as its size and quantity of electrodes are suitable for the researcher's goal and the type of volunteer that will be used ${ }^{31}$.

The EEG is a method of recording and analyzing electrical activity of the brain used in the evaluation of sleep ${ }^{8,9}$, cerebral maturation $^{11}$, functional development ${ }^{9}$, detection of aspects of diseases and seizures in neonates ${ }^{3-6}$, especially preterm infants. With regard to the aEEG, its action of compressing data and reducing the time needed for evaluation of results optimized the care performed by NICUs and improved the diagnostic pattern of some diseases. However, its limitations in continuous monitoring, mainly related to seizures, were also recognized.

Finally, the geodesic sensor net EEG was shown as an attempt to solve problems that other types of EEGs had, related to the positioning and the number of electrodes used, which had limited information capture and harmed the integration of signals captured in different parts of the brain. When comparing all these techniques, the variation in the opinion of the authors is noted, each one adapting their thinking on this subject to a different situation. However, many defend the necessity of combining conventional EEG and aEEG to attain reliable results, and they admit an uncertainty regarding the use of the geodesic sensor net EEG in routine clinical practice.

Our review found that, based on the analyzed articles, the use of these technologies is variable and depends on the context in which each is used. In a research environment, the use of a geodesic sensor net EEG would be of great value, as it allows a large amount of data to be analyzed, which may be useful in studies and research related to diseases and symptoms, such as seizures, a current challenge for neonatal neuromonitoring, as well as aspects of neurological development and functional studies. However, in view of its large technological load, it requires large funding, a fact that must be taken into consideration when it is acquired. In addition, before an accurate assessment of its clinical benefits over other devices has been carried out, in the context of the service in which it will be applied, it may be too great a risk to be purchased immediately by a large neonatology service.

Regarding the clinical environment, what may offer more benefits would be the use of both the conventional EEG and aEEG ${ }^{4,5,10,15,18,24,34}$, as this allows the combination of their functions, enabling, for example, the detection of a greater number of subclinical seizures, as the two technologies each have some detection faults that can be solved by using them together. While these technologies still require skilled people to use them, they have a good cost-effective relationship because of the large number of different types of diagnostics and analyses it can offer.

The individual use of the aEEG still has researchers who support it, due to the reduced need for trained personnel and the greater ease of interpretation, using a condensed result that could quickly become a diagnosis. However, the fact that there are few electrodes to evaluate several developing brain areas makes it less reliable for use with high-risk neonates, which is the case in many premature babies, as problems in unmonitored brain areas may not be noticed. Even so, it is important to emphasize that aEEG is part of the diagnostic parameters of certain diseases and its use is recommended in the absence of the possibility of acquiring the combination of conventional EEG and aEEG.

The future of neonatal neuromonitoring, aimed primarily at premature infants, is in improving the accuracy of diagnosis of syndromes, diseases, seizures and functional delays, 
which has not yet been achieved even with the combination of more than one EEG technique. A device that provides, for example, a computational means of tracking EEG brain maturation in preterm infants, allowing the comparison of recorded and expected EEG maturation, would be a useful tool for clinicians in the $\mathrm{NICU}^{39}$. It is expected that increasingly small and practical equipment that can perform continuous monitoring at the patient's bedside will be developed. Facilitating the placement of the electrodes should also be a goal of future research, as this is a challenge in very premature babies with small cephalic perimeters and fragile skulls. Placement may currently take hours, just for this initial part of the examination, which is not suitable for a NICU where there are many delicate patients to be attended to. Research related to the change in the material used by the electrodes has already occurred, although no study was found that evaluates its application in the daily clinical context. The geodesic sensor net EEG is also a promising option for the future. Its increased data capture and easy application of electrodes suggests its potential in facilitating the diagnosis in neonates, especially of subclinical diseases. Thus, although there have been many recent advances, electroencephalography in preterm neonates is still a challenge worldwide and requires neurophysiologists and researchers who are willing to adapt and re-evaluate traditional methods to achieve a result that can meet most needs.

\section{References}

1. Geddes LA, Baker LE. Principles of Applied Biomedical Instrumentation. 3rd ed. New York: Wiley-Interscience; 1989.

2. Poblet JM. Introducción a la bioingeniería. Barcelona: Marcombo-Boixareu; 1988.

3. Sánchez Fernández I, Sansevere AJ, Guerriero RM, Buraniqi E, Pearl PL, Tasker RC, et al. Time to electroencephalography is independently associated with outcome in critically ill neonates and children. Epilepsia. 2017 Mar;58(3):420-8. https://doi.org/10.1111/epi.13653

4. Tao JD, Mathur AM. Using amplitude-integrated EEG in neonatal intensive care [Review]. J Perinatol. 2010 Oct;30(1 Suppl):S73-81. https://doi.org/10.1038/jp.2010.93

5. El-Dib M, Chang T, Tsuchida TN, Clancy RR. Amplitude-integrated electroencephalography in neonates. Pediatr Neurol. 2009 Nov;41 (5):315-26. https://doi.org/10.1016/j.pediatrneurol.2009.05.002

6. Toet MC, Lemmers PM. Brain monitoring in neonates. Early Hum Dev. 2009 Feb;85(2):77-84. https://doi.org/10.1016/j.earlhumdev.2008.11.007

7. Bonifacio SL, Glass HC, Peloquin S, Ferriero DM. A new neurological focus in neonatal intensive care. Nat Rev Neurol. 2011 Aug;7(9):485-94. https://doi.org/10.1038/nrneurol.2011.119

8. Castro Conde JR, González Barrios D, González Campo C, González González NL, Reyes Millán B, Sosa AJ. Visual and Quantitative Electroencephalographic Analysis in Healthy Term Neonates Within the First Six Hours and the Third Day of Life. Pediatr Neurol. 2017 Dec;77(1):54-60.e1. https://doi.org/10.1016/j.pediatrneurol.2017.04.024

9. Dereymaeker A, Pillay K, Vervisch J, De Vos M, Van Huffel $\mathrm{S}$, Jansen $\mathrm{K}$, et al. Review of sleep-EEG in preterm and term neonates. Early Hum Dev. 2017 Oct;113(1):87-103. https://doi.org/10.1016/j.earlhumdev.2017.07.003

10. Shellhaas RA. Continuous electroencephalography monitoring in neonates. Curr Neurol Neurosci Rep. 2012 Aug;12(4):429-35. https://doi.org/10.1007/s11910-012-0275-6

11. Birca A, Vakorin VA, Porayette P, Madathil S, Chau V, Seed M, et al. Interplay of brain structure and function in neonatal congenital heart disease. Ann Clin Transl Neurol. 2016 Aug;3(9):708-22. https://doi.org/10.1002/acn3.336

12. Meijer EJ, Niemarkt HJ, Raaijmakers IP, Mulder AM, Pul C, Wijn PF, et al. Interhemispheric connectivity estimated from EEG time-correlation analysis in preterm infants with normal follow-up at age of five. Physiol Meas. 2016 Dec;37(12):2286-98. https://doi.org/10.1088/1361-6579/37/12/2286
13. Koolen N, Dereymaeker A, Räsänen O, Jansen K, Vervisch J, Matic V, et al. Early development of synchrony in cortical activations in the human. Neuroscience. 2016 May;322(1):298-307. https://doi.org/10.1016/j.neuroscience.2016.02.017

14. Winckler $\mathrm{M}$ et al. The role of amplitude integrated electroencephalogram in very low-birth-weight preterm infants: a literature review. Neuropediatrics. 2017 Dec;48(6):413-9. https://doi.org/10.1055/s-0037-1604403

15. Soubasi V, Mitsakis K, Sarafidis K, Griva M, Nakas CT, Drossou V. Early abnormal amplitude-integrated electroencephalography (aEEG) is associated with adverse short-term outcome in premature infants. Eur J Paediatr Neurol. 2012 Nov;16(6):625-30. https://doi.org/10.1016/j.ejpn.2012.02.008

16. Shany E, Meledin I, Gilat S, Yogev H, Golan A, Berger I. In and ex utero maturation of premature infants electroencephalographic indices. Clin Neurophysiol. 2014 Feb;125(2):270-6. https://doi.org/10.1016/j.clinph.2013.06.185

17. Parmelee AH Jr, Schulte FJ, Akiyama Y, Wenner WH, Schultz MA, Stern E. Maturation of EEG activity during sleep in premature infants. Electroencephalogr Clin Neurophysiol. 1968 Apr;24(4):319-29. https://doi.org/10.1016/0013-4694(68)90193-4

18. Vasiljević B, Maglajlić-Djukić S, Gojnić M. The prognostic value of amplitude-integrated electroencephalography in neonates with hypoxic-ischemic encephalopathy. Vojnosanit Pregl. 2012 Jun;69(6):492-9. https://doi.org/10.2298/VSP1206492V

19. Löfhede J, Seoane F, Thordstein M. Textile electrodes for EEG recording: a pilot study. Sensors (Basel). 2012 Dec;12(12):16907-19. https://doi.org/10.3390/s121216907

20. Norman E, Rosén I, Vanhatalo S, Stjernqvist K, Okland O, Fellman $V$, et al. Electroencephalographic response to procedural pain in healthy term newborn infants. Pediatr Res. 2008 Oct;64(4):429-34. https://doi.org/10.1203/PDR.0b013e3181825487

21. El-Dib M, Massaro AN, Glass P, Bulas D, Badrawi N, Orabi A, et al. Early amplitude integrated electroencephalography and outcome of very low birth weight infants. Pediatr Int. $2011 \mathrm{Jun}$;53(3):315-21. https://doi.org/10.1111/j.1442-200X.2010.03270.x

22. Eklund JM, Fontana N, Pugh E, McGregor C, Yielder P, James A et al. Automated sleep-wake detection in neonates from cerebral function monitor signals. In: 2014 IEEE 27th International Symposium On Computer-based Medical Systems; 2014 May 27-29; New York, United States.. Ontário: University of Ontario Institute of Technology; 2014.

23. Barbeau DY, Weiss MD. Sleep disturbances in newborns. Children (Basel). 2017 Oct;4(10):90-106. https://doi.org/10.3390/children4100090 
24. Bruns N, Blumenthal S, Meyer I, Klose-Verschuur S, Felderhoff-Müser U, Müller H. Application of an amplitude-integrated EEG monitor (cerebral function monitor) to neonates. J Vis Exp. 2017 Sep;1(127):1-9. https://doi.org/10.3791/55985

25. Paz-Levy D, Schreiber L, Erez O, Goshen S, Richardson J, Drunov $\mathrm{V}$, et al. Inflammatory and vascular placental lesions are associated with neonatal amplitude integrated EEG recording in early premature neonates. PLoS One. 2017 Jun;12(6):e0179481. https://doi.org/10.1371/journal.pone.0179481

26. Thorngate L, Foreman SW, Thomas KA. Quantification of neonatal amplitude-integrated EEG patterns. Early Hum Dev. 2013 Dec;89(12):931-7. https://doi.org/10.1016/j.earlhumdev.2013.09.018

27. Bruns N, Dransfeld F, Hüning B, Hobrecht J, Storbeck T, Weiss C, et al. Comparison of two common aEEG classifications for the prediction of neurodevelopmental outcome in preterm infants. Eur $\mathrm{J}$ Pediatr. 2017 Feb;176(2):163-71. https://doi.org/10.1007/s00431-016-2816-5

28. Weeke LC, Dix LM, Groenendaal F, Lemmers PM, Dijkman KP, Andriessen P, et al. Severe hypercapnia causes reversible depression of aEEG background activity in neonates: an observational study. Arch Dis Child Fetal Neonatal Ed. 2017 Sep;102(5):F383-8. https://doi.org/10.1136/archdischild-2016-311770

29. Jasper HH. Appendix to report to Committee on Clinical Examination in EEG: the ten-twenty electrode system of the International Federation. Electroencephalogr Clin Neurophysiol. 1958;10(1):371-5.

30. Tucker DM. Spatial sampling of head electrical fields: the geodesic sensor net. Electroencephalogr Clin Neurophysiol. 1993 Sep;87(3):154-63. https://doi.org/10.1016/0013-4694(93)90121-B

31. Luu P, Tucker DM, Englander R, Lockfeld A, Lutsep H, Oken B. Localizing acute stroke-related EEG changes: assessing the effects of spatial undersampling. J Clin Neurophysiol. 2001 Jul;18(4):302-17. https://doi.org/10.1097/00004691-200107000-00002
32. Myers MM, Grieve PG, Stark RI, Isler JR, Hofer MA, Yang J, et al. Family nurture intervention in preterm infants alters frontal cortical functional connectivity assessed by EEG coherence. Acta Paediatr. 2015 Jul;104(7):670-7. https://doi.org/10.1111/apa.13007

33. Tóth B, Urbán G, Háden GP, Márk M, Török M, Stam CJ, et al. Large-scale network organization of EEG functional connectivity in newborn infants. Hum Brain Mapp. 2017 Aug;38(8):4019-33. https://doi.org/10.1002/hbm.23645

34. Rosén I. The physiological basis for continuous electroencephalogram monitoring in the neonate. Clin Perinatol. 2006 Sep;33(3):593-611. https://doi.org/10.1016/j.clp.2006.06.013

35. Shah DK, Zempel J, Barton T, Lukas K, Inder TE. Electrographic seizures in preterm infants during the first week of life are associated with cerebral injury. Pediatr Res. 2010 Jan;67(1):102-6. https://doi.org/10.1203/PDR.0b013e3181bf5914

36. Walsh BH, Murray DM, Boylan GB. The use of conventional EEG for the assessment of hypoxic ischaemic encephalopathy in the newborn: a review. Clin Neurophysiol. $2011 \mathrm{Jul}$;122(7):1284-94. https://doi.org/10.1016/j.clinph.2011.03.032

37. Pavlidis E, Lloyd RO, Mathieson S, Boylan GB. A review of important electroencephalogram features for the assessment of brain maturation in premature infants. Acta Paediatr. 2017 Sep;106(9):1394-408. https://doi.org/10.1111/apa.13956

38. Lamblin MD, Touzery AV. EEG in the neonatal unit. Neurophysiologie Clinique/clinical. Neurophysiology. 2015;45(1):87-95. https://doi.org/10.1016/j.neucli.2014.11.007

39. O'TooleJM et al. Estimating functional brain maturity in very and extremely preterm neonates using automated analysis of the electroencephalogram. Clin Neurophysiol. 2016 Aug;127(8):2910-8. https://doi.org/10.1016/j.clinph.2016.02.024 